\title{
Smoke-free legislation and childhood hospitalisations for respiratory tract infections
}

\author{
Jasper V. Been ${ }^{1,2,3,4}$, Christopher Millett ${ }^{5}$, John Tayu Lee ${ }^{5}$, \\ Constant P. van Schayck ${ }^{1,2}$ and Aziz Sheikh ${ }^{1,2,6}$
}

\begin{abstract}
Affiliations: ' $S$ chool for Public Health and Primary Care, Maastricht University, Maastricht, The Netherlands ${ }^{2}$ Centre of Medical Informatics, Usher Institute of Population Health Sciences and Informatics, The University of Edinburgh, Edinburgh, UK. ${ }^{3}$ Dept of Paediatrics, Maastricht University Medical Centre, Maastricht, The Netherlands. 'Division of Neonatology, Erasmus University Medical Centre - Sophia Children's Hospital, Rotterdam, The Netherlands. ${ }^{5}$ Dept of Primary Care and Public Health, School of Public Health, Imperial College London, London, UK. 'Division of General Internal Medicine and Primary Care, Brigham and Women's Hospital/Harvard Medical School, Boston, MA, USA.
\end{abstract}

Correspondence: Jasper V. Been, Maastricht University Medical Centre, Dept of Paediatrics, P0 Box 5800, 6202 AZ Maastricht, The Netherlands. E-mail: jasper.beenamumc.nl

ABSTRACT Second-hand smoke exposure is a major risk factor for respiratory tract infections (RTIs). Although evidence suggests important early-life health benefits of smoke-free public environments, the impact on childhood RTIs is unclear. We investigated the association between England's smoke-free legislation and childhood RTI hospitalisations.

We used the Hospital Episode Statistics database to obtain nationwide data on hospital admissions for acute RTIs among children ( $<15$ years of age) from 2001 to 2012. Hospitalisation counts were disaggregated by month, age group, sex and small-area level, and linked to urbanisation, region, deprivation index and corresponding population estimates. Negative binomial regression analyses were adjusted for confounders, seasonal variation, temporal autocorrelation, population-size changes and underlying incidence trends. Models allowed for sudden and gradual changes following the smoke-free legislation. We performed sensitivity and subgroup analyses, and estimated number of events prevented.

We analysed 1651675 hospital admissions. Introduction of smoke-free legislation was followed by an immediate reduction in RTI admissions $(-3.5 \%, 95 \%$ CI $-4.7--2.3 \%)$, this mainly being attributable to a decrease in lower RTI admissions $(-13.8 \%$, 95\% CI $-15.6--12.0 \%)$. The reductions in admissions for upper RTI were more incremental.

The introduction of national smoke-free legislation in England was associated with 11000 fewer hospital admissions per year for RTIs in children.

@ERSpublications

Smoke-free legislation in England was associated with a drop in paediatric respiratory infection admissions http://ow.ly/L4XCL

Editorial comment in: Eur Respir J 2015; 46: 601-603 [DOI: 10.1183/13993003.00883-2015]

This article has supplementary material available from erj.ersjournals.com

A press release for this article is available from erj.ersjournals.com/site/misc/presspack.xhtml

Received: Jan 272015 | Accepted after revision: March 242015 | First published online: May 282015

Clinical trial: This study is registered at www.clinicaltrials.gov with identifier number NCT01920165.

Conflict of interest: None declared.

Copyright OERS 2015 


\section{Introduction}

Respiratory tract infections (RTIs) are extremely common among children, particularly during the first few years of life [1]. Although the majority are mild and self limiting, severe RTIs are estimated to be responsible for 11.9 million hospitalisations and 1.4 million deaths worldwide among children $<5$ years of age [2]. The majority of this disease burden is experienced in low- and middle-income countries; achieving sustained reductions in the incidence of severe RTIs is therefore crucial to realise the fourth Millennium Development Goal of reducing global mortality in children $<5$ years of age $[2,3]$.

Second-hand smoke (SHS) exposure is an important preventable exposure predisposing to RTIs $[4,5]$. Associations between SHS exposure and bronchitis, bronchiolitis, middle ear infection, and RTIs in general are well established [6-8]. As a result, the vast majority of the estimated 166000 deaths and 6.6 million disability-adjusted life-years resulting from SHS exposure among children each year are due to RTIs [9]. Given that $40 \%$ of children worldwide are regularly exposed to SHS, the scope for prevention is substantial [9].

SHS exposure can effectively be reduced by creating comprehensive smoke-free public environments enacted through national legislation [10]. Furthermore, such regulations are associated with an increased adoption of smoke-free homes, providing additional benefit, particularly to young children, whose carers represent the primary source of tobacco smoke exposure [11-13]. Accumulating evidence now demonstrates the public health benefits of smoke-free legislation, including effects on paediatric respiratory health [14]. Asthma hospitalisations decreased among children following smoke-free legislation in Scotland and England, UK $[15,16]$, as did paediatric emergency department visits for asthma in Lexington-Fayette County in Kentucky, USA [17]. In a recent meta-analysis that included these studies, we demonstrated that implementation of smoke-free legislation was followed by a $10 \%(95 \%$ CI $5-15 \%, \mathrm{p}=0.0001)$ drop in paediatric hospital attendance for asthma [14]. No national studies evaluating the association between smoke-free legislation and RTIs among children were identified, which constituted a key knowledge gap [14].

Given the strong association between SHS and childhood RTIs, and the potential importance of smoke-free legislation in achieving the internationally agreed Millennium Development Goal target [6-9], we investigated the association between the 2007 implementation of smoke-free public environments in England and rates of hospital admissions for RTIs among children.

\section{Methods}

This study was performed according to a pre-specified and registered research protocol (www.ClinicalTrials.gov identifier NCT01920165).

\section{Ethical considerations}

This study was reviewed by the National Health Service South East Scotland Research Ethics Service and The University of Edinburgh Centre for Population Health Sciences Ethics Review Group (Edinburgh, UK). Both committees provided an exemption from formal ethical assessment based on the use of anonymised and unidentifiable data.

\section{Introduction of smoke-free legislation}

The intervention under study was the law prohibiting smoking in enclosed public places that was implemented in England on July 1, 2007 [18]. From this date, smoking was prohibited in public places and workplaces in England, with very few exemptions [19]. Overall, compliance with the smoke-free law has been high, with $>98 \%$ of premises and vehicles found to be smoke-free in the first year following its implementation [20].

\section{Outcome definitions}

The primary outcome was the rate of unplanned hospital admissions for acute RTIs among children. We also separately examined admission rates for acute upper and lower RTIs. All unplanned hospitalisations were included when either a primary or first secondary diagnosis of an acute RTI was recorded. We used the following International Classification of Diseases (10th revision) codes used to identify acute RTIs. 1) Upper RTIs: A37, H66-H67, J02.0, J00-J06 and J09-J11 (excluding J10.0 and J11.0). 2) Lower RTIs:

Support statement: This work was supported by the Thrasher Research Fund (Early Career Award TRF9124 to J.V. Been), the Netherlands Lung Foundation (Long Term Fellowship 3.4.12.128FE to J.V. Been), the International Pediatric Research Foundation (Young Investigator Exchange Programme grant to J.V. Been) and The Commonwealth Fund, a private independent foundation based in New York, NY, USA (to A. Sheikh). The views presented here are those of the authors and not necessarily those of The Commonwealth Fund, its directors, officers or staff. Funding information for this article has been deposited with FundRef. 
J10.0, J11.0, J12-J18, J20-J22 and J40-J42. To prevent overlap, admissions containing both a diagnosis of an upper and a lower acute RTI were counted as a lower RTI only as this was considered the more severe outcome. Furthermore, admissions with a primary diagnosis of asthma were excluded to prevent overlap with a previous study assessing the impact of the English smoke-free legislation on paediatric asthma hospitalisations [16]. Transfers between hospitals following initial admission were not included in order to avoid double-counting.

\section{Data sources}

National hospital admission data were obtained from the Hospital Episode Statistics database [21]. The Hospital Episode Statistics database is managed by the Health and Social Care Information Centre (Leeds, UK), and collects individual-level data on all admissions to National Health Service hospitals in England and Wales. For the purpose of this study, we collected data for the whole of England, where the Hospital Episode Statistics database is estimated to cover $\sim 99 \%$ of all hospital admissions (Hospital Episode Statistics; personal communication, 2013). The at-risk population was defined based on mid-year population estimates obtained from the UK Office for National Statistics website [22].

\section{Study population and period}

We restricted our analyses to include only children aged $0-14$ years in order to minimise the potential effect of active smoking. The data covered the period ranging from January 1, 2001, to December 31, 2012. This was the maximum time period surrounding the introduction of smoke-free legislation for which both numerator (i.e. number of hospitalisations) and denominator (i.e. population at risk) data were available.

\section{Data handling and covariates}

Population estimates and hospitalisation counts were derived according to strata based on all possible combinations of the following covariates: age group (0-4, 5-9 and 10-14 years), sex, region (Greater London, North East, North West, Yorkshire and the Humber, East Midlands, West Midlands, East of England, South East, and South West), urbanisation (rural versus urban), Index of Multiple Deprivation (IMD) quintile, admission month (categorical: January to December) and admission year (continuous). See the online supplementary material for more detail.

\section{Statistical analyses}

We used negative binomial regression analysis to assess the association between the July 2007 introduction of smoke-free legislation and RTI admission rates [16, 23, 24]. The method takes into account the underlying time trend in RTI admissions by including a continuous variable for time, and estimates both the immediate ("step") and gradual ("slope") change in RTI admission rate after implementation of smoke-free legislation [14]. The model yields an admission rate ratio (ARR) for each variable (including for the step and slope indicators) adjusted for other covariates in the model. For the step change, the ARR represents the ratio of the hospital admission rate (i.e. the incidence of hospital admissions over time) in the post-legislation versus the pre-legislation period [16]. The ARR for the slope change represents the ratio of the admission rate for any given year post-legislation versus the previous year. Seasonality was modelled using a categorical variable for admission month, and potential confounders were adjusted for: age group, sex, IMD quintile, urbanisation level and English region. See the online supplementary material for more detail.

\section{Sensitivity analysis}

On September 4, 2006, the heptavalent pneumococcal conjugate vaccine (PCV7) was introduced into the national vaccination schedule in England, with a catch-up programme for children born after September 2004. Given its temporal proximity to the introduction of smoke-free legislation, we performed a pre-specified sensitivity analysis to test whether any effect attributed to the law may in fact be explained by PCV7 introduction. See the online supplementary material for more detail.

\section{Subgroup analysis}

Evidence is increasing that the impact of tobacco control policies is variable across socioeconomic statuses [25]. In a post hoc subgroup analysis, we therefore assessed whether the association between smoke-free legislation and RTI admissions varied according to socioeconomic status by adding interaction terms between IMD quintile and the step and slope indicators to the main model.

\section{Absolute impact estimation}

We estimated the total number of RTI admissions prevented in the first 5 years following the smoke-free legislation by subtracting actual monthly admission counts from those estimated by the model without the law effects. These counterfactual estimates were calculated using the $\beta$-values derived from the primary model but leaving out the step and slope indicators of the legislation [16]. 


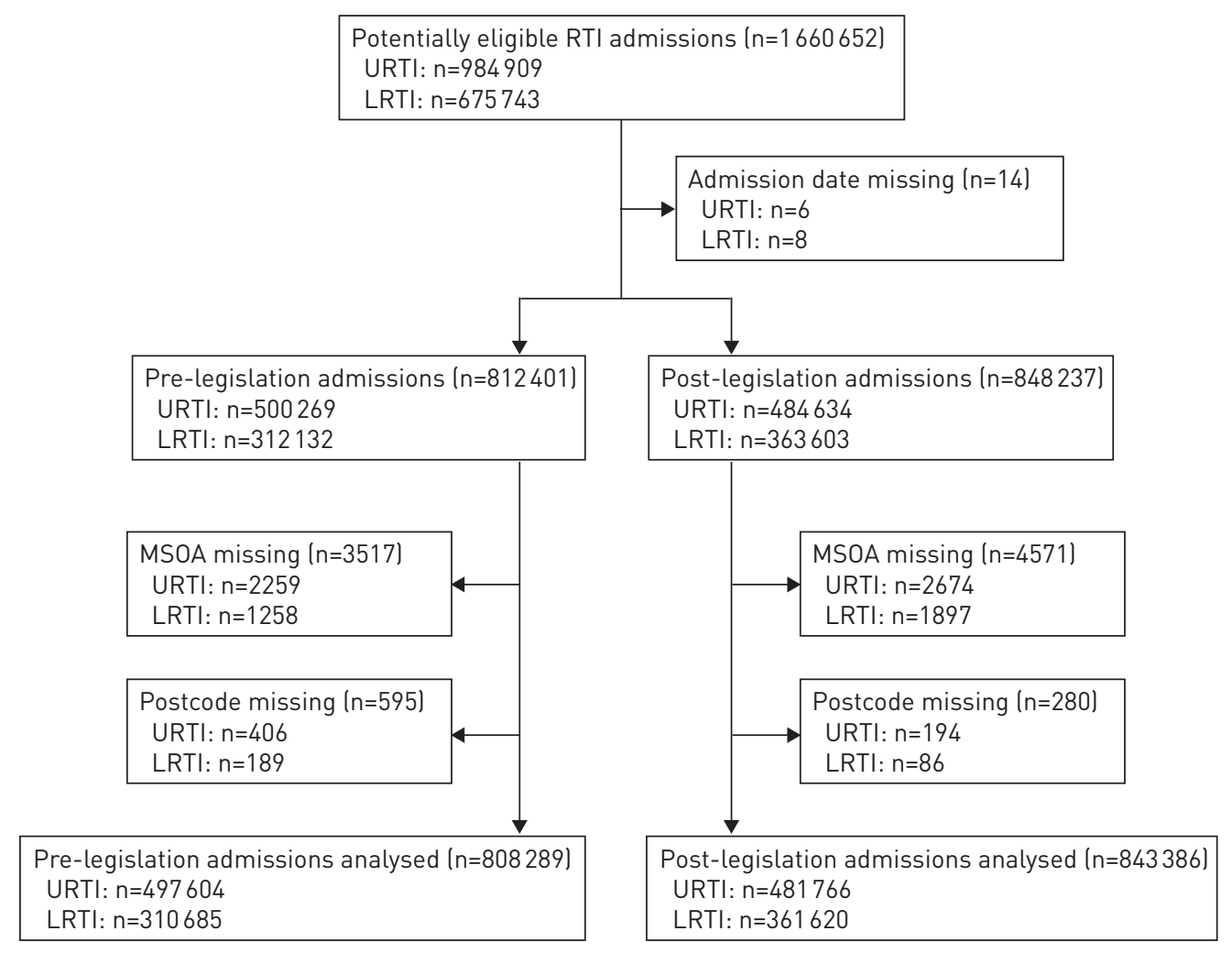

FIGURE 1 Study inclusion flowchart. RTI: respiratory tract infection; URTI: upper respiratory tract infection; LRTI: lower respiratory tract infection; MSOA: middle layer super output area.

\section{Results}

There were 1660652 hospital admissions for acute RTIs in children over the study period. After exclusion of cases with missing admission dates, middle layer super output areas and/or postcodes, 1651675 (99.5\%) admissions were available for analysis (fig. 1). Upper RTIs constituted 59.3\% ( $\mathrm{n}=979370)$ of all RTI admissions during the study period.

On visual inspection of temporal incidence patterns, there was a clear seasonal pattern that was most pronounced with lower RTI admissions, with peaks in November and December, and troughs between June and September in each year (fig. 2a). The vast majority of RTI admissions (85\%) occurred among $0-4$-year-olds and close to $60 \%$ were in boys (table 1). Regional variation was present, with rates that were highest in northern regions and urban areas. There was a clear association between area-level deprivation index and RTI admission rates, with $>30 \%$ of RTIs occurring in the most deprived quintile. Demographic characteristics were similar in those experiencing upper and lower RTI admissions (table S1).

In the negative binomial regression model, introduction of smoke-free legislation was associated with a significant immediate reduction in overall RTI admissions $(-3.5 \%$ (95\% CI $-4.7--2.3 \%), \mathrm{p}<0.001)$ (table 2). This was then followed by a small, sustained, gradual reduction in overall RTI admission rate $(-0.5 \%(95 \%$ CI $-0.9--0.1 \%)$ per year, $\mathrm{p}=0.017)$.

The effects of smoke-free legislation on upper and lower RTIs differed (table 3). A small, but statistically significant, initial increase was seen in admissions for upper RTIs $(+1.9 \%(95 \% \mathrm{CI}+0.5-+3.2 \%), \mathrm{p}=0.005)$, followed by a gradual and sustained decrease in yearly rate $(-1.9 \%(95 \% \mathrm{CI}-2.3--1.5 \%)$ per year, $\mathrm{p}<0.001)$. Conversely, smoke-free legislation was associated with a large, instant drop in lower RTIs $(-13.8 \%$ (95\% CI $-15.6--12.0 \%), \mathrm{p}<0.001)$, with no clear subsequent temporal rate change $(+0.2 \%(95 \%$ $\mathrm{CI}-0.6-+0.9 \%)$ per year, $\mathrm{p}=0.701)$.

Additional modelling of the introduction of PCV7 in September 2006 did not have any major bearing on the estimated impact of smoke-free legislation for any outcome (table S2). In these models, PCV7 introduction was associated with a significant reduction in RTI admissions $(-1.5 \%$ (95\% CI $-2.6--0.3 \%)$, $\mathrm{p}=0.011$ ), with the greatest impact on lower RTI admissions.

The gradual, but not the immediate, impact of smoke-free legislation on RTI admissions varied according to socioeconomic status ( $\mathrm{p}$-value for interaction $<0.001$ and 0.608 , respectively). The gradual decrease in 

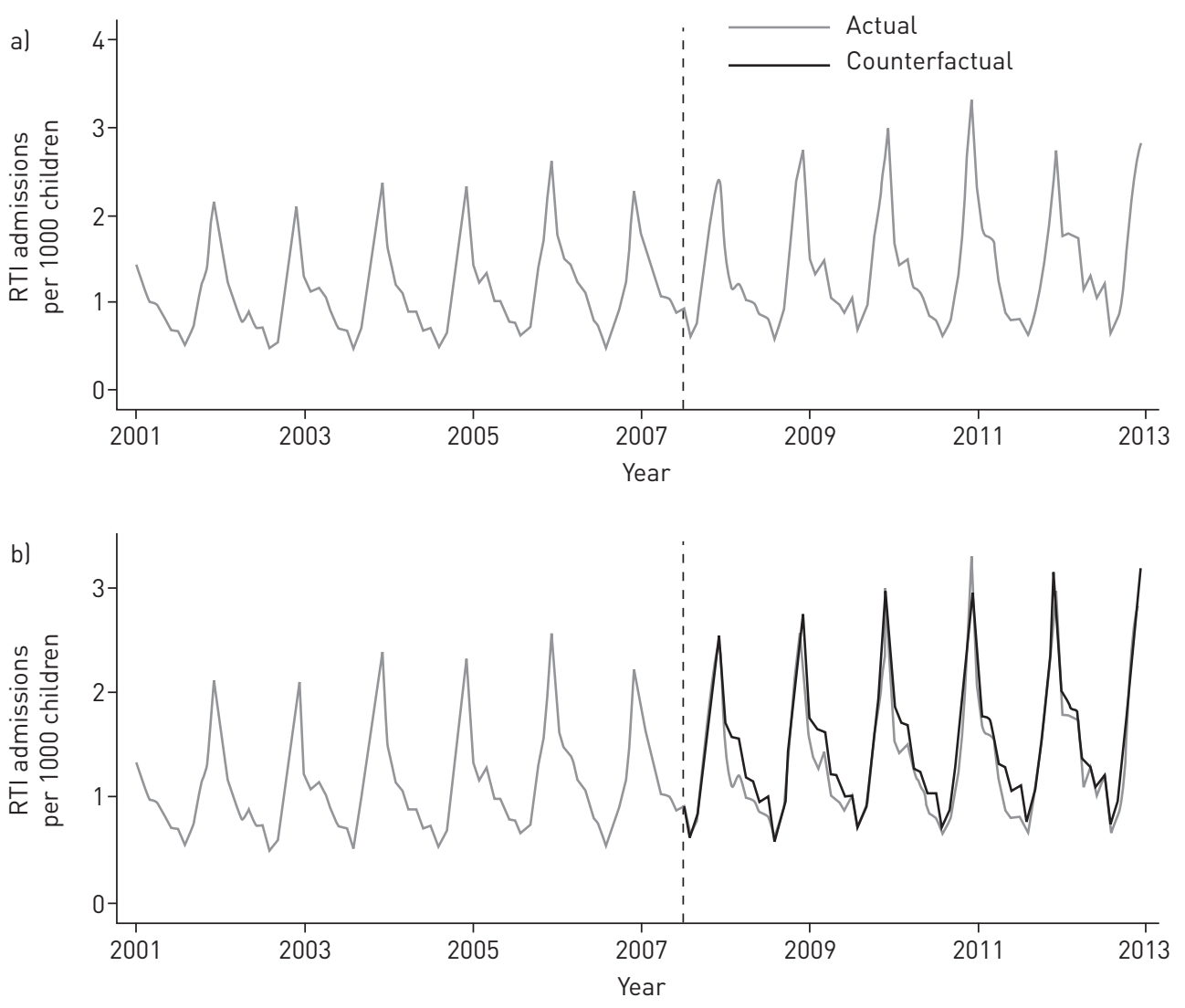

FIGURE 2 Actual respiratory tract infection (RTI) admission counts and model-predicted counts without smoke-free legislation effects. a) Actual monthly admission rates for RTIs; b) actual versus counterfactual admission rates for RTIs. Dashed line indicates introduction of smoke-free legislation.

RTI admissions was largest among the most deprived children $(-1.5 \%$ (95\% CI $-2.1--1.0 \%)$ per year, $\mathrm{p}<0.001$ versus most affluent group) (table S3).

In order to estimate the impact of smoke-free legislation in absolute terms, we compared actual numbers of RTI admissions during the post-legislation period with those projected from the model without the legislation effects (fig. 2b). In the first five full years following its introduction, smoke-free legislation was associated with the prevention of an estimated 54489 RTI hospital admissions among children across England.

\section{Discussion}

We have undertaken the first national evaluation investigating the association between the introduction of legislation prohibiting smoking in public places and hospital admissions for RTIs in children, this work demonstrating an immediate reduction in lower RTI admissions, and a more gradual, incremental reduction in upper RTI admissions. Building on related recent work, this work adds to the growing body of evidence for the health benefits of smoke-free public environments on early-life health [14].

With $>1.6$ million events evaluated, this is one of the most comprehensive assessments of the impact of smoke-free legislation on child health ever undertaken [14]. The study was performed according to a pre-specified study protocol that was registered prior to undertaking data analysis. We used nationwide hospitalisation data in order to maximise power and minimise selection bias. Our data were seasonally adjusted, thereby inherently accounting for variations in corresponding environmental exposures such as ambient temperature and air pollution [16]. RTI admissions were evaluated at monthly intervals over several years surrounding the introduction of smoke-free legislation. Exploiting the full time period in which necessary data were available, we were able to reliably estimate underlying incidence trends as well as longer-term cumulative changes following the ban.

Our study has a number of limitations. Common to evaluation of nationally implemented public health interventions, the intervention was not randomly allocated and a control group, in the usual sense of the term, was lacking [26]. As a quasiexperimental study, it is thus intrinsically at risk of bias [27]. 


\begin{tabular}{|c|c|c|}
\hline Characteristic & $\begin{array}{c}\text { Hospitalisations } \\
\mathrm{n}(\%)\end{array}$ & $\begin{array}{l}\text { Mean admission rate } \\
\text { per } 1000 \text { children }\end{array}$ \\
\hline \multicolumn{3}{|l|}{ Sex } \\
\hline Male & 957628 (58.0) & 1.42 \\
\hline Female & $694047(42.0)$ & 1.08 \\
\hline \multicolumn{3}{|l|}{ Age } \\
\hline $0-4$ years & $1410090(85.4)$ & 3.21 \\
\hline $5-9$ years & $166919(10.1)$ & 0.39 \\
\hline $10-14$ years & $47666(4.5)$ & 0.17 \\
\hline \multicolumn{3}{|l|}{ Region } \\
\hline Greater London & $156378(9.5)$ & 0.77 \\
\hline East Midlands & $138663(8.4)$ & 1.25 \\
\hline East of England & 140636 (8.5) & 0.96 \\
\hline North East & $114100(6.9)$ & 1.81 \\
\hline North West & 306085 (18.5) & 1.72 \\
\hline South East & $244500(14.8)$ & 1.14 \\
\hline South West & $139062(8.4)$ & 1.12 \\
\hline West Midlands & $215459(13.0)$ & 1.50 \\
\hline Yorkshire and the Humber & 196792 (11.9) & 1.49 \\
\hline \multicolumn{3}{|l|}{ Urbanisation level } \\
\hline Urban & $1411152(85.4)$ & 1.30 \\
\hline Rural & $240523(14.6)$ & 1.04 \\
\hline \multicolumn{3}{|l|}{ Index of Multiple Deprivation } \\
\hline Quintile $1^{\#}$ & 239432 (14.5) & 0.93 \\
\hline Quintile 2 & 256556 (15.5) & 1.04 \\
\hline Quintile 3 & $290240(17.6)$ & 1.18 \\
\hline Quintile 4 & 354880 (21.5) & 1.35 \\
\hline Quintile 5 & 510567 (30.9) & 1.68 \\
\hline
\end{tabular}

${ }^{\#}$ : least deprived; ${ }^{\text {I: }}$ most deprived.

Overwhelming data from numerous countries, however, support the link between smoke-free legislation and reduction of SHS exposure $[10,11,13]$. In keeping with this link, a dose-response association between the comprehensiveness of smoke-free legislation and its associated health benefits has been clearly demonstrated [28]. As the home environment is the primary source for SHS exposure, particularly among young children, it is important to note that through norm-spreading, smoke-free public places and workplaces are also associated with the increased adoption of smoke-free homes [12, 13]. Studies in different UK countries have demonstrated consequential reductions in SHS exposure among children following the introduction of smoke-free legislation [29-32]. In England, reported smoking in the home among adult smokers dropped from $65 \%$ to $55 \%(\mathrm{p}=0.001)$ within 6 months and the number of homes becoming smoke-free among children with smoking parents increased from $34 \%$ to $41 \%(\mathrm{p}<0.001)$ within a year [11,32]. Explorative interrogation of Health Survey for England data revealed a $62 \%$ relative drop in self-reported smoking in the home during our study's post-ban period (from $23 \%$ to $14 \%, \mathrm{p}<0.0001$ ) [33]. Reported SHS exposure among children on public transport also dropped significantly [34]. Reduced exposure in these various locations probably contributed to the observed increase in the number of children with undetectable salivary cotinine, a biomarker of SHS exposure [32]. In addition to the established health benefits among adults, reproducible reductions in severe paediatric asthma exacerbations have been demonstrated following the introduction of smoke-free legislation in various countries [15-17], including England [16]. Given these observations, and the clear link between SHS exposure and RTIs among children, it is highly plausible that the observed reduction in RTI admissions following the introduction of smoke-free legislation is indeed attributable to this public health intervention. However, as with all quasiexperimental work, findings should be interpreted with care, and in the light of the full body of evidence on the impact of smoke-free legislation on early-life and population health [14, 28].

Interrupted time series modelling assumes that all other factors influencing the outcome remain unchanged [26]. This is especially important with regard to the time period surrounding the intervention under study. We identified the September 2006 introduction of PCV7 as a potential violator of this assumption a priori. The sensitivity analyses that accounted for PCV7 support the robustness of the impact estimation of the smoke-free legislation. The 2009 H1N1 outbreak constitutes another potential violator of the assumption of temporal stability [35]. Visual inspection of temporal patterns did not 


\begin{tabular}{|c|c|c|}
\hline Characteristic & $\operatorname{ARR}(95 \% \mathrm{CI})$ & p-value \\
\hline Time (per year) & $1.031(1.028-1.033)$ & \\
\hline Smoke-free legislation & $0.965(0.953-0.977)$ & $<0.001$ \\
\hline Time since smoke-free legislation (per year) & $0.995(0.991-0.999)$ & 0.017 \\
\hline \multicolumn{3}{|l|}{ Month } \\
\hline January & Ref. & \\
\hline February & $0.917(0.904-0.930)$ & \\
\hline March & $0.899(0.887-0.912)$ & \\
\hline April & $0.682(0.672-0.693)$ & \\
\hline May & $0.664(0.654-0.674)$ & \\
\hline June & $0.549(0.540-0.557)$ & \\
\hline July & $0.579(0.571-0.588)$ & \\
\hline August & $0.370(0.364-0.377)$ & \\
\hline September & $0.493(0.486-0.501)$ & \\
\hline October & $0.777(0.766-0.789)$ & \\
\hline November & $1.055(1.040-1.070)$ & \\
\hline December & $1.471(1.451-1.492)$ & \\
\hline \multicolumn{3}{|l|}{ Sex } \\
\hline Female & Ref. & \\
\hline Male & $1.265(1.257-1.273)$ & \\
\hline \multicolumn{3}{|l|}{ Age } \\
\hline $0-4$ years & Ref. & \\
\hline $5-9$ years & $0.129(0.127-0.130)$ & \\
\hline $10-14$ years & $0.055(0.054-0.055)$ & \\
\hline \multicolumn{3}{|l|}{ Region } \\
\hline Greater London & Ref. & \\
\hline East Midlands & 1.798 (1.772-1.825) & \\
\hline East of England & $1.462(1.441-1.484)$ & \\
\hline North East & $2.459(2.422-2.497)$ & \\
\hline North West & $2.288(2.256-2.321)$ & \\
\hline South East & $1.729(1.705-1.754)$ & \\
\hline South West & $1.682(1.658-1.707)$ & \\
\hline West Midlands & $1.955(1.926-1.983)$ & \\
\hline Yorkshire and the Humber & $2.032(2.003-2.061)$ & \\
\hline \multicolumn{3}{|l|}{ Urbanisation level } \\
\hline Rural & Ref. & \\
\hline Urban & $1.008(1.000-1.016)$ & \\
\hline \multicolumn{3}{|l|}{ Index of Multiple Deprivation } \\
\hline Quintile $1^{\#}$ & Ref. & \\
\hline Quintile 2 & $1.082(1.071-1.092)$ & \\
\hline Quintile 3 & $1.202(1.191-1.214)$ & \\
\hline Quintile 4 & $1.336(1.322-1.349)$ & \\
\hline Quintile 5ף & $1.497(1.481-1.514)$ & \\
\hline
\end{tabular}

ARR: admission rate ratio. ${ }^{\#}$ : least deprived; " : most deprived.

suggest an important overall effect on childhood RTI admission rates. If anything, a consequential increase in RTI admissions would bias the impact estimation of the smoking ban towards the null.

Hospital Episode Statistics data are being increasingly used in clinical studies [36]. Data validity is continuously audited and coding accuracy is high [36,37]. Nonetheless, there is the possibility that registration of hospital admissions may have improved over the study period, which would have underestimated the true impact of smoke-free legislation [37]. Furthermore, in the absence of a unique patient identifier in our dataset, we were unable to distinguish between first and subsequent admissions for individual children.

The effect of smoke-free legislation on RTI admissions was much larger among adults, as estimated by a recent meta-analysis [28]. This meta-analysis also provided evidence for a dose-dependent benefit of the degree of coverage by the smoke-free legislation [28]. No studies assessing its impact on adult RTI admissions in England are available for comparison. Our finding of an initial, large drop in lower RTI admissions is in line with published adult studies, which focussed on bronchitis and pneumonia [28, 38, 39]. 
TABLE 3 Multivariable negative binomial regression model for upper and lower respiratory tract infection (RTI) hospitalisations

\begin{tabular}{|c|c|c|c|c|}
\hline \multirow[t]{2}{*}{ Characteristic } & \multicolumn{2}{|l|}{ Upper RTIs } & \multicolumn{2}{|l|}{ Lower RTIs } \\
\hline & $\operatorname{ARR}(95 \% \mathrm{CI})$ & p-value & $\operatorname{ARR}(95 \% \mathrm{CI})$ & p-value \\
\hline Time (per year) & $1.018(1.015-1.020)$ & & $1.066(1.059-1.072)$ & \\
\hline Smoke-free legislation & $1.019(1.005-1.032)$ & 0.005 & $0.862(0.844-0.880)$ & $<0.001$ \\
\hline Time since smoke-free legislation (per year) & $0.981(0.977-0.985)$ & $<0.001$ & $1.002(0.994-1.009)$ & 0.701 \\
\hline \multicolumn{5}{|l|}{ Month } \\
\hline January & Ref. & & Ref. & \\
\hline February & $1.053(1.037-1.069)$ & & $0.801(0.783-0.820)$ & \\
\hline March & $1.094(1.077-1.110)$ & & $0.713(0.696-0.730)$ & \\
\hline April & $0.851(0.838-0.865)$ & & $0.538(0.525-0.551)$ & \\
\hline May & $0.860(0.846-0.873)$ & & $0.463(0.451-0.475)$ & \\
\hline June & $0.728(0.716-0.740)$ & & $0.358(0.348-0.367)$ & \\
\hline July & $0.770(0.758-0.783)$ & & $0.370(0.360-0.380)$ & \\
\hline August & $0.513(0.505-0.522)$ & & $0.222(0.216-0.229)$ & \\
\hline September & $0.663(0.652-0.674)$ & & $0.336(0.327-0.345)$ & \\
\hline October & $0.987(0.972-1.002)$ & & $0.597(0.583-0.612)$ & \\
\hline November & $1.098(1.082-1.115)$ & & $1.038(1.015-1.061)$ & \\
\hline December & $1.311(1.292-1.331)$ & & $1.584(1.550-1.618)$ & \\
\hline \multicolumn{5}{|l|}{ Sex } \\
\hline Female & Ref. & & Ref. & \\
\hline Male & $1.311(1.303-1.320)$ & & $1.219(1.207-1.232)$ & \\
\hline \multicolumn{5}{|l|}{ Age } \\
\hline $0-4$ years & Ref. & & Ref. & \\
\hline $5-9$ years & $0.135(0.134-0.136)$ & & $0.130(0.128-0.131)$ & \\
\hline $10-14$ years & $0.056(0.055-0.056)$ & & $0.057(0.056-0.058)$ & \\
\hline \multicolumn{5}{|l|}{ Region } \\
\hline Greater London & Ref. & & Ref. & \\
\hline East Midlands & $2.226(2.192-2.261)$ & & $1.412(1.378-1.447)$ & \\
\hline East of England & $1.739(1.712-1.766)$ & & $1.203(1.175-1.233)$ & \\
\hline North East & $3.081(3.032-3.131)$ & & $1.816(1.770-1.862)$ & \\
\hline North West & 2.985 (2.942-3.029) & & $1.564(1.528-1.602)$ & \\
\hline South East & $2.079(2.048-2.110)$ & & $1.385(1.353-1.417)$ & \\
\hline South West & $1.940(1.910-1.971)$ & & $1.447(1.413-1.482)$ & \\
\hline West Midlands & $2.466(2.429-2.504)$ & & $1.462(1.427-1.497)$ & \\
\hline Yorkshire and the Humber & $2.456(2.419-2.493)$ & & $1.631(1.593-1.670)$ & \\
\hline \multicolumn{5}{|l|}{ Urbanisation level } \\
\hline Rural & Ref. & & Ref. & \\
\hline Urban & $1.030(1.022-1.038)$ & & $0.959(0.947-0.972)$ & \\
\hline \multicolumn{5}{|l|}{ Index of Multiple Deprivation } \\
\hline Quintile $1^{\#}$ & Ref. & & Ref. & \\
\hline Quintile 2 & $1.099(1.087-1.110)$ & & $1.061(1.044-1.078)$ & \\
\hline Quintile 3 & $1.227(1.215-1.240)$ & & $1.166(1.147-1.185)$ & \\
\hline Quintile 4 & $1.356(1.341-1.370)$ & & $1.280(1.259-1.302)$ & \\
\hline Quintile 5 & $1.523(1.507-1.540)$ & & $1.418(1.392-1.444)$ & \\
\hline
\end{tabular}

ARR: admission rate ratio. " ${ }^{\#}$ : least deprived; " : most deprived.

We included a long follow-up period after the smoke-free legislation was implemented, which may account for the small cumulative impact as compared with adult studies [28, 38, 39]. Additional studies among young populations and with longer follow-up are required to investigate this further. Another aspect potentially explaining greater benefit among adults is that they are likely to spend a larger amount of time in public places than children and thus benefit more from these environments becoming smoke free. Part of the effect among adults may also be explained by a reduction in active smoking, which is unlikely to be an important factor in our evaluation given the population's age composition. Furthermore, we excluded admissions for asthma, which may have contaminated the RTI admissions in the adult studies [38, 39].

An unanticipated finding of the current study is the disparate association between smoke-free legislation and upper and lower RTI admissions. Very few observational studies have explored the distinct effects of smoke exposure on upper and lower airways [40]. DuITs et al. [41] found that environmental smoke exposure significantly increased the risk of upper, but not lower, RTIs among infants whose mothers did 
not smoke. A recent study in mice showed that upper airways were more susceptible to the subacute effects of smoke exposure, whereas the inflammatory response in lower airways persisted much longer [42]. Differential associations between SHS exposure and viral versus bacterial host-pathogen interactions may furthermore contribute to the different temporal response patterns observed for upper and lower RTI admissions [4, 5]. Because both upper and lower RTI admissions showed a net reduction following smoke-free legislation, these considerations, although mechanistically interesting, do not affect the validity of the findings.

Implementation of smoke-free public environments through national legislation constitutes an integral part of the World Health Organization's approach to worldwide tobacco control [43], which is necessary to reduce the substantial global health burden associated with smoking [9]. Although 180 nations have now ratified the Framework Convention for Tobacco Control, only $\sim 15 \%$ of the world's population is currently covered by comprehensive smoke-free legislation [43]. This is the first evaluation to demonstrate a reduction in paediatric RTI admissions following implementation of national smoke-free legislation [14]. This equates with annual cost savings of approximately $£ 17$ million (approximately $€ 24$ million) over 5 years, based on an estimate derived from combining our counterfactual estimates with National Health Service reference costs (see the online supplementary material for more detail). Given the considerable inequalities in smoking and attributable adverse health outcomes [25, 44], our finding of a differential health impact of smoke-free legislation on the most deprived children is particularly encouraging. Additional studies in other countries are now needed to confirm our findings. Only a small minority of all RTIs among children require hospitalisation and impact estimation using primary care data may help to better appreciate the population health benefit. There is a particular need for studies in low- and middle-income countries, where the majority of the disease burden associated with SHS exposure lies [9]. This will help to estimate the potential contribution of smoke-free legislation to reach the fourth Millennium Development Goal of decreasing global child mortality.

Randomised controlled trials of interventions are ideally needed to definitively establish causality, but the chance of these being mounted in the context of legislation banning smoking in public places is believed to be negligible. In the absence of such trials, we have undertaken a rigorous quasiexperimental analysis that clearly shows that the introduction of smoke-free legislation was associated with a significant reduction in hospital admissions for acute RTIs among children in England. When taken together with national data indicating that the smoking ban was also associated with substantial reductions in smoking within the home and related work on the public health benefits of smoke-free legislation, the findings from this national analysis strengthen recommendations for the global implementation of legislation prohibiting smoking in public places.

\section{Acknowledgements}

We thank the staff at the Health and Social Care Information Centre for their help in protocol development and data extraction. We are furthermore grateful to Rob Elton (The University of Edinburgh, Edinburgh, UK), Valéria Lima Passos (Maastricht University, Maastricht, Netherlands), Jamie Pearce (The University of Edinburgh) and Robin Prescott (The University of Edinburgh) for providing advice on data analysis. We thank Andy Stoddart at the Edinburgh Health Services Research Unit (Edinburgh, UK) for his support in the calculation of cost estimates.

\section{References}

1 Rudan I, O’Brien KL, Nair H, et al. Epidemiology and etiology of childhood pneumonia in 2010: estimates of incidence, severe morbidity, mortality, underlying risk factors and causative pathogens for 192 countries. J Global Health 2013; 3: 10401

2 Nair H, Simoes EA, Rudan I, et al. Global and regional burden of hospital admissions for severe acute lower respiratory infections in young children in 2010: a systematic analysis. Lancet 2013; 381: 1380-1390.

3 Walker CL, Rudan I, Liu L, et al. Global burden of childhood pneumonia and diarrhoea. Lancet 2013; 381: 1405-1416.

4 Garmendia J, Morey P, Bengoechea JA. Impact of cigarette smoke exposure on host-bacterial pathogen interactions. Eur Respir J 2012; 39: 467-477.

5 Feldman C, Anderson R. Cigarette smoking and mechanisms of susceptibility to infections of the respiratory tract and other organ systems. J Infect 2013; 67: 169-184.

6 Jones LL, Hashim A, McKeever T, et al. Parental and household smoking and the increased risk of bronchitis, bronchiolitis and other lower respiratory infections in infancy: systematic review and meta-analysis. Respir Res 2011; $12: 5$.

7 Jones LL, Hassanien A, Cook DG, et al. Parental smoking and the risk of middle ear disease in children: a systematic review and meta-analysis. Arch Pediatr Adolesc Med 2012; 166: 18-27.

8 DiFranza JR, Masaquel A, Barrett AM, et al. Systematic literature review assessing tobacco smoke exposure as a risk factor for serious respiratory syncytial virus disease among infants and young children. BMC Pediatr 2012; 12: 81 .

9 Oberg M, Jaakkola MS, Woodward A, et al. Worldwide burden of disease from exposure to second-hand smoke: a retrospective analysis of data from 192 countries. Lancet 2011; 377: 139-146.

10 Callinan JE, Clarke A, Doherty $\mathrm{K}$, et al. Legislative smoking bans for reducing secondhand smoke exposure, smoking prevalence and tobacco consumption. Cochrane Database Syst Rev 2010; CD005992. 
11 Lee JT, Glantz SA, Millett C. Effect of smoke-free legislation on adult smoking behaviour in England in the 18 months following implementation. PLoS One 2011; 6: e20933.

12 Nazar GP, Lee JT, Glantz SA, et al. Association between being employed in a smoke-free workplace and living in a smoke-free home: evidence from 15 low and middle income countries. Prev Med 2014; 59: 47-53.

13 Cheng KW, Glantz SA, Lightwood JM. Association between smokefree laws and voluntary smokefree-home rules. Am J Prev Med 2011; 41: 566-572.

14 Been JV, Nurmatov UB, Cox B, et al. Effect of smoke-free legislation on perinatal and child health: systematic review and meta-analysis. Lancet 2014; 383: 1549-1560.

15 Mackay D, Haw S, Ayres JG, et al. Smoke-free legislation and hospitalizations for childhood asthma. N Engl J Med 2010; 363: 1139-1145.

16 Millett C, Lee JT, Laverty AA, et al. Hospital admissions for childhood asthma after smoke-free legislation in England. Pediatrics 2013; 131: e495-e501.

17 Rayens MK, Burkhart PV, Zhang M, et al. Reduction in asthma-related emergency department visits after implementation of a smoke-free law. J Allergy Clin Immunol 2008; 122: 537-541.e3.

18 Public Health England. The smoke-free (exemptions and vehicles) regulations 2007. Statutory Instruments 2007 no. 765. http://webarchive.nationalarchives.gov.uk/20091005123812/opsi.gov.uk/si/si2007/uksi_20070765_en_1 Date last accessed: March 21, 2014.

19 Smokefree England. www.smokefreeengland.co.uk Date last accessed: March 13, 2014.

20 Department of Health. Smokefree England - one year on. www.smokefreeengland.co.uk/files/dhs 01 01-one-year-on-report-final.pdf Date last accessed: March 21, 2014. Date last updated: 2008.

21 Health and Social Care Information Centre. Hospital Episode Statistics. www.hscic.gov.uk/hes Date last accessed: March 21, 2014.

22 Office for National Statistics. Geography. www.ons.gov.uk/ons/guide-method/geography/ons-geography/index.html Date last accessed: March 21, 2014.

23 Glantz SA, Gibbs E. Changes in ambulance calls after implementation of a smoke-free law and its extension to casinos. Circulation 2013; 128: 811-813.

24 Hilbe JM. Negative binomial regression. Cambridge, Cambridge University Press, 2011.

25 Hill S, Amos A, Clifford D, et al. Impact of tobacco control interventions on socioeconomic inequalities in smoking: review of the evidence. Tob Control 2014; 23: e89-e97.

26 Biglan A, Ary D, Wagenaar AC. The value of interrupted time-series experiments for community intervention research. Prev Sci 2000; 1: 31-49.

27 Freemantle N, Wood J, Crawford F. Evidence into practice, experimentation and quasi experimentation: are the methods up to the task? J Epidemiol Community Health 1998; 52: 75-81.

28 Tan CE, Glantz SA. Association between smoke-free legislation and hospitalizations for cardiac, cerebrovascular, and respiratory diseases: a meta-analysis. Circulation 2012; 126: 2177-2183.

29 Akhtar PC, Currie DB, Currie CE, et al. Changes in child exposure to environmental tobacco smoke (CHETS) study after implementation of smoke-free legislation in Scotland: national cross sectional survey. BMJ 2007; 335: 545.

30 Holliday JC, Moore GF, Moore LA. Changes in child exposure to secondhand smoke after implementation of smoke-free legislation in Wales: a repeated cross-sectional study. BMC Public Health 2009; 9: 430.

31 Moore GF, Currie D, Gilmore G, et al. Socioeconomic inequalities in childhood exposure to secondhand smoke before and after smoke-free legislation in three UK countries. J Public Health 2012; 34: 599-608

32 Jarvis MJ, Sims M, Gilmore A, et al. Impact of smoke-free legislation on children's exposure to second-hand smoke: cotinine data from the Health Survey for England. Tob Control 2012; 21: 18-23.

33 UK Data Service. Health Survey for England. http://discover.ukdataservice.ac.uk/series/?sn=2000021 Date last accessed: August 13, 2014.

34 The NHS Information Centre. Health Survey for England - Volume 1: Healthy lifestyles: knowledge, attitudes and behaviour. www.hscic.gov.uk/catalogue/PUB00415/heal-surv-life-know-atti-beha-eng-2007-rep-v2.pdf Date last accessed: August 22, 2014. Date last updated: 2008.

35 Novel Swine-Origin Influenza A (H1N1) Virus Investigation Team, Dawood FS, Jain S, et al. Emergence of a novel swine-origin influenza A (H1N1) virus in humans. N Engl J Med 2009; 360: 2605-2615.

36 Sinha S, Peach G, Poloniecki JD, et al. Studies using English administrative data (Hospital Episode Statistics) to assess health-care outcomes - systematic review and recommendations for reporting. Eur J Public Health 2013; 23: 86-92.

37 Burns EM, Rigby E, Mamidanna R, et al. Systematic review of discharge coding accuracy. J Public Health 2012; 34: $138-148$.

38 Naiman A, Glazier RH, Moineddin R. Association of anti-smoking legislation with rates of hospital admission for cardiovascular and respiratory conditions. CMAJ 2010; 182: 761-767.

39 Kent BD, Sulaiman I, Nicholson TT, et al. Acute pulmonary admissions following implementation of a national workplace smoking ban. Chest 2012; 142: 673-679.

40 Baxi R, Sharma M, Roseby R, et al. Family and carer smoking control programmes for reducing children's exposure to environmental tobacco smoke. Cochrane Database Syst Rev 2014; CD001746.

41 Duijts L, Jaddoe VW, Hofman A, et al. Maternal smoking in prenatal and early postnatal life and the risk of respiratory tract infections in infancy. The Generation R study. Eur J Epidemiol 2008; 23: 547-555.

42 Huvenne W, Perez-Novo CA, Derycke L, et al. Different regulation of cigarette smoke induced inflammation in upper versus lower airways. Respir Res 2010; 11: 100.

43 World Health Organization. WHO report on the global tobacco epidemic 2013. Enforcing bans on tobacco advertising, promotion and sponsorship. www.who.int/tobacco/global_report/2013/en Date last accessed: March 21, 2014. Date last updated: 2013.

44 Hiscock R, Bauld L, Amos A, et al. Socioeconomic status and smoking: a review. Ann NY Acad Sci 2012; 1248: 107-123. 